\title{
Editorial
}

\section{Limnologists and oceanographers - two scientific families that should talk together more freely}

The United Nations have declared the year 2003 as the International Year of Fresh Water. The purpose is to raise the awareness of the significance of fresh water and to focus our attention on using water resources in a sustainable way as individuals, communities, countries, and as a global family of concerned citizens. Because of the scarcity of fresh water in many countries, particularly in Africa, equitable distribution of fresh water among humans on the one hand, and among humans and ecosystems on the other hand, will be one of the most pressing obligations of mankind in this century. Aquatic sciences, including the socio-economics of water, are needed as a basis for sound political decisions and actions. This year, the spring, summer and fall numbers of Aquatic Sciences $(A S)$ will each contain one or two articles in the Water Policy section that address fresh water issues at the interface of the natural sciences, social sciences, and public policy.

Aquatic Sciences - Research Across Boundaries is not exclusively a fresh water journal. As indicated under "Scope and Intent" (see back cover and web site of the Journal), it also includes studies of marine systems. Our intent is to increase the number of papers from the marine field, so that approximately $50 \%$ of articles published in $A S$ will be from fresh water systems and $50 \%$ from marine systems. Reaching this goal will take some time because $A S$ has traditionally been a limnological journal. We hope that the project SOLAS (Surface Ocean - Lower Atmosphere Study, http://www.uea.ac.uk/env/solas/welcome.htm) will be a source of marine articles for $A S$. SOLAS is a multidisciplinary and global-scale research program that has been developed by the international scientific community "to achieve quantitative understanding of the key biogeochemical-physical interactions and feedbacks between the ocean and atmosphere, and how this coupled system affects and is affected by climate and environmental change". The interaction between limnologists and oceanographers is still in its infancy but with a promising "adulthood" ahead. The two can contribute a great deal to each other. "Lakes are test tubes of oceans" the father of aquatic chemistry, Werner Stumm, used to say. An important goal of the Journal is to serve as a forum for an ongoing exchange between different scientific "families", e.g., between limnologists and oceanographers.

In aquatic systems, most processes are interdependent, e.g., redox-cycling of metals and metal mobilization are linked to the transformation of natural organic matter. In sunlit aquatic systems, these linked processes are enhanced by sunlight and determine to a great extent the biological availability of metals and of organic carbon. As demonstrated by many research groups, the lightinduced redox cycling of trace metals, either essential and/or toxic to aquatic microorganisms, results in an increase in their bioavailability. In the case of natural organic matter (NOM), light has contrasting effects on NOM bioavailability, generally rendering bioavailable NOM bio-recalcitrant and vice-versa. Light-induced alteration of natural organic matter is one of the major research interests of aquatic photochemists, both oceanographers and limnologists. In his essay on "Sunburnt organic matter: Biogeochemistry of light-altered substrate" (Limnology and Oceanography Bulletin 11(4), December 2002), Oliver C. Zafiriou states that “... a central trend will be towards elucidating the abiotic photoalteration of organic matter, the resultant changes in its biological properties, and the biological responses. Multidisciplinary studies will develop this rich, challenging theme." The $4^{\text {th }} 2003$ issue of $A S$ will largely be devoted to themes involving trace metals and natural organic matter, including biogenic ligands. It will be composed of articles solicited at two international conferences: (i) "Biogeochemical Controls on the Mobility and Bioavailability of Metals in Soils and Groundwater", International Workshop on Monte Verità, Switzerland (March 2-7, 2003), and (ii) "Impact of Photochemical Processes in the Hydrosphere" Symposium at the $225^{\text {th }}$ American Chemical Society Meeting, New Orleans, LA, USA (March 23-27, 2003). 
In addition to original research papers, and comprehensive overviews and reviews, $A S$ also publishes short critical reviews. These articles should predict in what direction an area of cross-boundary research is/should be heading in the next 5 to 10 years. In addition, papers presenting new ideas and hypotheses, based on observations and first results, will be included in $A S$ as well. These papers also should describe the type of experiments needed to verify (or falsify) proposed hypotheses. The review process of these "hypothesis papers" will be even more rigorous than that of original research papers.
I think it is fair to say that the re-launching of Aquatic Sciences has started successfully and that a solid level of quality among all articles has been established. I hope this level can be maintained and I look forward to receiving articles for publication in $A S$ from you, our reader, and from within your research group, Department and Institute.

Barbara Sulzberger, Editor-in-Chief sulzberger@eawag.ch 